\title{
Corrigendum: A CRISPR New World: Attitudes in the Public toward Innovations in Human Genetic Modification
}

\author{
Steven M. Weisberg*, Daniel Badgio and Anjan Chatterjee* \\ Department of Neurology, Center for Cognitive Neuroscience, University of Pennsylvania, Philadelphia, PA, United States
}

Keywords: genetic modification, online survey, Mechanical Turk, metaphor, CRISPR

A corrigendum on

A CRISPR New World: Attitudes in the Public toward Innovations in Human Genetic Modification

by Weisberg SM, Badgio D, Chatterjee A. Front Public Health (2017) 5:117. doi: 10.3389/ fpubh.2017.00117

Error in Figure/Table

In the original article, there was a mistake in Figure 2 as published. The original Figure 2 contained a typo in Figure 2. The sentence "These advances mean that they might be UNABLE" should have read "These advances mean that they might be $A B L E$ ". This typo was solely in the Figure. The correct version of the vignette was presented to participants. The corrected Figure 2 appears below. The authors apologize for this error and state that this does not change the scientific conclusions of the article in any way.

\section{OPEN ACCESS}

Edited and Reviewed by:
Paul Russell Ward,
Flinders University, Australia

*Correspondence:

Steven M. Weisberg stweis@mail.med.upenn.edu; Anjan Chatterjee anjan@mail.med.upenn.edu

Specialty section: This article was submitted to Public Health Policy, a section of the journal Frontiers in Public Health

Received: 23 May 2017 Accepted: 21 June 2017

Published: 06 July 2017

Citation:

Weisberg SM, Badgio D and Chatterjee A (2017) Corrigendum: A CRISPR New World: Attitudes in the Public toward Innovations in

Human Genetic Modification.

Front. Public Health 5:161. doi: 10.3389/fpubh.2017.00161
A Recently, scientists have figured out precise, cheap, and easy ways to modify genes. These advances mean that they might be able to correct disease-causing genes, like those that cause hemophilia, cystic fibrosis, and Huntington's disease. It means that they might be able to add genes that are protective for future problems like the cognitive decline of aging or the risk of contracting immune diseases. It also means they might be able to improve genes to enhance normal traits, like height and maybe even intelligence. As the methods are worked out, there are risks. For individuals, it could have unintended consequences, or lead to unexpected mutations. For society, it could lead to eugenics.

Should we be actively researching these technologies?

$\begin{array}{ccccccc}\text { Absolutely Not } & \text { No } & \text { Probably Not } & \text { Not Sure } & \text { Probably Yes } & \text { Yes } & \text { Absolutely Yes } \\ \text { 0 } & 0 & 0 & 0 & 0 & 0 & 0\end{array}$

B

\begin{tabular}{ccccc} 
Vignette Number & Word 1 & Word 2 & Word 3 & Word 4 \\
\hline $\mathbf{1}$ & Modify & Correct & Add & Improve \\
$\mathbf{2}$ & Edit & Find and replace & Insert & Refine \\
$\mathbf{3}$ & Engineer & Fix & Build in & Optimize \\
$\mathbf{4}$ & Hack & Debug & Program & Upgrade \\
$\mathbf{5}$ & Perform surgery on & Repair & Implant & Augment
\end{tabular}

FIGURE 2 | Genetic modification vignette. The vignette shown to participants in the Modify + Risk condition from Study 1 (A). The Likert scale was displayed after the vignette had been on the screen by itself for $30 \mathrm{~s}$. Words in bold were replaced by the corresponding words in the table (B) for participants in the other metaphor conditions. The words in italics were placed after the first sentence for the Study 2 Risk-before condition and were removed for the No Risk condition in Study 1. Bold and italic fonts are for emphasis only and were not seen by participants. See Supplementary Material for all vignettes for both studies in full. 
Conflict of Interest Statement: The authors declare that the research was conducted in the absence of any commercial or financial relationships that could be construed as a potential conflict of interest.
Copyright (c) 2017 Weisberg, Badgio and Chatterjee. This is an open-access article distributed under the terms of the Creative Commons Attribution License (CC BY).

The use, distribution or reproduction in other forums is permitted, provided the original author(s) or licensor are credited and that the original publication in this journal is cited, in accordance with accepted academic practice. No use, distribution or reproduction is permitted which does not comply with these terms. 